\title{
Three new chondrosarcoma cell lines: one grade III conventional central chondrosarcoma and two dedifferentiated chondrosarcomas of bone
}

\author{
Jolieke G van Oosterwijk1, Danielle de Jong², Maayke AJH van Ruler ${ }^{1}$, Pancras CW Hogendoorn', \\ PD Sander Dijkstra ${ }^{3}$, Carla SP van Rijswijk ${ }^{4}$, Isidro Machado ${ }^{5}$, Antonio Llombart-Bosch ${ }^{5}$, Karoly Szuhai ${ }^{2}$ \\ and Judith VMG Bovée ${ }^{1 *}$
}

\begin{abstract}
Background: Chondrosarcoma is the second most common primary sarcoma of bone. High-grade conventional chondrosarcoma and dedifferentiated chondrosarcoma have a poor outcome. In pre-clinical research aiming at the identification of novel treatment targets, the need for representative cell lines and model systems is high, but availability is scarce.

Methods: We developed and characterized three cell lines, derived from conventional grade III chondrosarcoma (L835), and dedifferentiated chondrosarcoma (L2975 and L3252) of bone. Proliferation and migration were studied and we used COBRA-FISH and array-CGH for karyotyping and genotyping. Immunohistochemistry for p16 and p53 was performed as well as TP53 and IDH mutation analysis. Cells were injected into nude mice to establish their tumorigenic potential.

Results: We show that the three cell lines have distinct migrative properties, L2975 had the highest migration rate and showed tumorigenic potential in mice. All cell lines showed chromosomal rearrangements with complex karyotypes and genotypic aberrations were conserved throughout late passaging of the cell lines. All cell lines showed loss of CDKN2A, while TP53 was wild type for exons 5-8. L835 has an IDH1 R132C mutation, L2975 an IDH2 R172W mutation and L3252 is IDH wild type.

Conclusions: Based on the stable culturing properties of these cell lines and their genotypic profile resembling the original tumors, these cell lines should provide useful functional models to further characterize chondrosarcoma and to evaluate new treatment strategies.
\end{abstract}

Keywords: Bone neoplasm, Chondrosarcoma, Cell line, IDH1, IDH2, p16

\section{Background}

Chondrosarcoma is a malignant bone neoplasm characterized by the deposition of a hyaline cartilaginous extracellular matrix. With an incidence of 1:50,000 it typically occurs in adults in their $3^{\text {rd }}$ to $6^{\text {th }}$ decade of life. Chondrosarcoma represents a heterogeneous group of tumors. Primary central chondrosarcoma is defined by the formation of hyaline cartilage with decreasing matrix production in higher grades and constitutes about $80 \%$ of all chondrosarcomas

\footnotetext{
* Correspondence: j.v.m.g.bovee@lumc.nl

1Department of Pathology, Leiden University Medical Center, Albinusdreef 2, 2333 ZA Leiden, The Netherlands

Full list of author information is available at the end of the article
}

[1]. Dedifferentiated chondrosarcoma is characterized by a low-, or intermediate grade chondrosarcoma juxtaposed to a high grade anaplastic sarcoma and constitutes about $10 \%$ of all chondrosarcomas [2].

Both high grade conventional and dedifferentiated chondrosarcoma respond poorly to conventional chemoand/or radiotherapy, have a high metastatic rate, and consequently have a very poor prognosis [3]. It is because of these features that there is an urgent need for model systems in pre-clinical research aimed at evaluating new targeted treatment strategies for chondrosarcoma [4].

\section{Ciomed Central}

(c) 2012 van Oosterwijk et al.; licensee BioMed Central Ltd. This is an Open Access article distributed under the terms of the Creative Commons Attribution License (http://creativecommons.org/licenses/by/2.0), which permits unrestricted use, distribution, and reproduction in any medium, provided the original work is properly cited. 
Recently IDH1 and IDH2 mutations were found in conventional central and dedifferentiated chondrosarcomas [5]. IDH1 and IDH2 mutations are well known in gliomas [6], but are notoriously difficult to grow in culture [7]. This is a feature shared by, in particular, grade I chondrosarcomas. Recently, a new cell line derived from a grade II chondrosarcoma was published, $\mathrm{CH}-3573$ [8]. Over the last years, cell lines derived from dedifferentiated chondrosarcomas have been developed $[9,10]$. In the pursuit of expanding the panel of cell lines we have succeeded in creating three new chondrosarcoma cell lines. L835 is derived from a grade III conventional chondrosarcoma, while L2975 and L3252 originate from dedifferentiated chondrosarcomas of bone. These three new cell lines provide a valuable addition to the current panel of chondrosarcoma cell lines.

\section{Methods}

\section{Culture of human chondrosarcoma cells}

Tumor-tissue derived from three resected specimens derived from one conventional and two dedifferentiated chondrosarcomas were used for culture. Samples were coded and all procedures were performed according to the ethical guidelines "Code for Proper Secondary Use of Human Tissue in The Netherlands 2002" (Dutch Federation of Medical Scientific Societies http://www. federa.org/sites/default/files/bijlagen/coreon/codepropersecondaryuseofhumantissue1_0.pdf). Specimens were washed 3x with RPMI1640 (Gibco, Invitrogen LifeTechnologies, Scotland, UK) containing 1\% penicillin/ streptomycin $(100 \mathrm{U} / \mathrm{mL})$, minced with razor blades and immersed in collagenase dispase overnight. After washing, the cells were transferred into small collagencoated culture flasks and cultured in RPMI1640 supplemented with $20 \%$ heat inactivated Fetal Calf Serum (Gibco, Invitrogen Life-Technologies, Scotland, UK), 1\% L-glutamax, and 1\% penicillin/streptomycin (100U/ $\mathrm{mL})$. Cells were grown in a humidified incubator with $95 \%$ air and $5 \% \quad \mathrm{CO}_{2}$ and cultured until stably multiplying.

\section{COBRA-Fluoresence in-situ hybridization}

COBRA-FISH on metaphase slides was performed as described previously [11]. For each cell line several cell culture passages were studied (L835: passage 17 and 35, L2975: passage 20 and 30, L3252: passage 7, 8, and 20) and karyotypes were described for each cell line according to the International System of Human Cytogenetic Nomenclature (ISCN) 2009.

\section{Expression of cartilaginous genes}

RNA was isolated from L835 (passage 40), L2975 (passage 58), and L3252 (passage 21). Chondrogenic phenotype was assessed using RT-PCR for collagen I, IIB, III, and X, aggrecan, and SOX9 as described previously [12].

\section{Assessment of cell line identity}

DNA isolation from cell pellets was performed using the wizard genomic DNA purification kit (Promega, Madison, WI) according to manufacturer's instructions. DNA concentrations were measured using a Nanodrop ND-1000 spectrophotometer and quality was checked on a 1\% agarose gel stained with ethidium bromide. Identity of cell lines was confirmed using the PowerPlex ${ }^{\circledR} 1.2$ system (Promega Benelux BV, Leiden, The Netherlands). For L835 passage 36 was compared to primary tumor tissue, for L2975 passage 37 was used, and for L3252 passage 20 was compared to primary tumor tissue.

\section{Doubling time and migration assays}

The RTCA xCelligence system (Roche Applied Sciences, Almere, the Netherlands), based on cell-electrode substract impedance detection technology [13], was used for doubling time and migration assays. Prior to starting experiments cell number curves were run to determine optimal growth curves and for doubling time experiments cell lines were plated at a density of 1,000 cells per well for L2975 and L3252 and 10,000 cells per well for L835 in growth medium (10\% FCS in RPMI1640). For migration experiments, 100,000 cells were optimal.

For doubling time assays, 30 minutes after plating, view-plates were loaded into the RTCA station in the cell culture incubator. Cell index (CI) was acquired every hour.

Proliferation was monitored for 400 hrs. Every day plates were taken from the machine and most representative areas were photographed using a Zeiss axiovert 40C light microscope (Rijswijk, the Netherlands).

For migration assays, lower wells of the SIM plates (migration plates) were filled with growth medium (20\% FCS in RPMI1640) as a chemoattractant, and cells were plated in the top wells in empty buffer (RPMI1640 only). CIM plates with $8 \mu \mathrm{m}$ pores were loaded into the RTCA station in the cell culture incubator immediately after plating and cell index (CI) was acquired every 5 minutes. Migration was monitored for 24 hrs. Experiments were performed in triplicate.

\section{Mutation analysis}

Mutation analysis was performed for TP53 (exons 5-8) [14], and IDH1 and -2 exons 4 [15] using direct sequencing of DNA as described $(14 ; 15)$. Mutation analysis for PIK3CA, KRAS, BRAF, EGFR was performed using hydrolysis probes assay [16] at L835 (passage 36), L2975 (passage 37), and L3252 (passage 20). Mutation analysis for TP53 was performed at those same passage numbers 
and IDH mutation analysis was performed at L835 passage 38 and 47, L2975 passage 31 and 46, and L3252 passage 20, as well as on DNA obtained from $\mathrm{CH}-3573$ [8]. To determine expression of the IDH mutated allele cDNA was generated using $1 \mu \mathrm{g}$ total RNA as described [12] for L835 (passage 38), L2975 (passage 31), and L3252 (passage 20). Primers were designed with primer3 software (http://frodo.wi.mit.edu/primer3/) and ordered from ISOGEN Bioscience BV (Maarssen, the Netherlands). PCR was done with the quantitative PCR core kit for SYBR green I supplemented with fluorescin (Eurogentec, Seraing, Belgium) on $0.2 \mu \mathrm{L}$ cDNA per reaction in an iCycler iQ Real-time Detection system (Bio-Rad Laboratories, Hercules, CA). PCR was done for 40 cycles. PCR products were purified using QIAquick PCR purification Kit (Qiagen, Hilden, Germany) according to manufacturer's instructions. Purified products were sequenced by Macrogen (Amstelveen, the Netherlands) and resulting sequences were analyzed using MutationSurveyor DNA Variant Analysis software (Softgenetics, UK). Primer sequences and annealing temperatures are listed in Table 1.

\section{Array-CGH analysis}

Array-CGH was performed on DNA derived from the primary tumor as well as from cultured cells of all three cases as described [17]. DNA of L835 passage 36, L2975 passage 37, and L3252 passage 20 was used. In brief, labeling of $1 \mu \mathrm{g}$ DNA was performed using the BioPrime Total Genomic Labeling System (Invitrogen Corporation, Carlsbad, CA) following the manufacturer's protocol. As reference, DNA from a commercial source (Promega Corporation, Madison, WI) was used. Labeled test and reference samples were mixed and hybridized as a gender mismatch. Hybridization was performed on an Agilent $105 \mathrm{k}$ oligonucleotide array according to manufacturer's instructions. Slides were scanned using the

\section{Table 1 IDH primers}

\begin{tabular}{|c|c|c|c|c|}
\hline Primer & & & $\mathrm{Tm}$ & $\begin{array}{l}\text { Product } \\
\text { size }\end{array}$ \\
\hline $\begin{array}{l}\text { IDH1 } \\
\text { genomic }\end{array}$ & Forward & CGGTCTTCAGAGAAGCCATT & 59.4 & 113 \\
\hline $\begin{array}{l}\text { IDH1 } \\
\text { genomic }\end{array}$ & Reverse & GCCAACATGACTTACTTGATCC & 58.6 & \\
\hline $\begin{array}{l}\text { IDH2 } \\
\text { genomic }\end{array}$ & Forward & AACATCCACGCCTAGTCC & 56.3 & 90 \\
\hline $\begin{array}{l}\mathrm{IDH} 2 \\
\text { genomic }\end{array}$ & Reverse & CAGTGGATCCCCTCTCCAC & 60.5 & \\
\hline IDH1 cDNA & Forward & CGGTCTTCAGAGAAGCCATT & 59.4 & 131 \\
\hline IDH1 CDNA & Reverse & AGGCCCAGGAACAACAAAAT & 56.4 & \\
\hline $\mathrm{IDH} 2$ CDNA & Forward & AGTGTGGCTGCAAGTGTGC & 60.0 & 365 \\
\hline IDH2 cDNA & Reverse & GAGATGGACTCGTCGGTGTT & 60.1 & \\
\hline
\end{tabular}

Agilent Scanner with $5 \mu \mathrm{m}$ scan resolution. Scan images were processed with the Feature Extraction Software and the generated raw data files were analyzed using Genomic Workbench (Agilent Technologies, Santa Clara, CA). In short, the mean of the background corrected and Lowess normalized $\log 2$ ratios of identical features was calculated. Normalization of ratios was done using the overall values as well as the values of the control reporter probes on the array. Aberrations were calculated using the ADM-2 algorithm with a threshold of 8.6 and displayed with a moving average of $1 \mathrm{Mb}$.

\section{Tumorigenicity in mice}

All the experimentation involving laboratory animals was approved by the Institutional Animal Care of Valencia University and the Local Government and was performed in accordance with the national legislation of Spain. Male nude mice were purchased from IFFACREDO (Lyon, France), and kept under specific pathogen-free conditions throughout the experiments. For each cell line, 2,000,000 cells were subcutaneously injected in a total of 3 mice ( 2 months old) under sterile conditions. Tumor was removed when size reached $4 \mathrm{~mm}$ in diameter and a fragment of non-necrotic tumor, about 3 to $5 \mathrm{~mm}^{3}$ in size, was used for xenografting into two new male nude mice. The second neoplasm was removed when the size reached $20 \mathrm{~mm}$ in diameter. From each tumor a part was snap-frozen in liquid nitrogen, a part fixed in formalin and embedded in paraffin, a part was used for xenografting into 2 new mice, and a part for further culturing of post-xenograft cell lines.

\section{(Immuno)histochemical analysis}

L835 (passage 35), L2975 (passage 55), and L3252 (passage 17) cells were fixed in formalin and prepared using the Shandon Cytoblock cell block preparation system (Thermo Scientific, Etten-Leur, the Netherlands). Cells were embedded in paraffin according to standard laboratory procedures for tissue fixation. Sections (4- $\mu$ m thick) of these paraffin blocks as well as from formalin fixed paraffin embedded original tumor tissue and xenograft passages, were used for $H \& E$, toluidine blue, and immunohistochemistry for ki67, p53, and p16 according to standard procedures [18]. Details of the antibodies can be found in Table 2 .

\section{Results}

\section{Clinicopathological data}

The tissue specimen of L835 was retrieved from the resection specimen of the local recurrence of a chondrosarcoma occurring in the left distal radius (Figure 1A) of a 54 year-old male. The primary tumor had been resected seven months earlier. Histological examination revealed a highly cellular cartilaginous neoplasm, with 
Table 2 Antibody properties

\begin{tabular}{|c|c|c|c|c|c|}
\hline Antibody & Clone & Dilution & Antigen retrieval & Blocking & Source \\
\hline p16 & g175-405 & 1:800 & Citrate & - & BD Pharmingen (550834) \\
\hline p53 & DO-7 & $1: 800$ & Citrate & - & Dako (M7001) \\
\hline Ki67 & MIB-1 & $1: 800$ & Citrate & - & Dako (M7240) \\
\hline
\end{tabular}

myxoid matrix changes and the presence of mitoses, and spindle cell changes at the edge of the lobuli, consistent with a primary central chondrosarcoma of bone, grade III according to Evans [19] (Figure 1E).
L2975 was derived from the resection of a metastasis of a dedifferentiated chondrosarcoma located at the spine of a 57 year-old male. The primary tumor was located at the right distal femur, and was originally

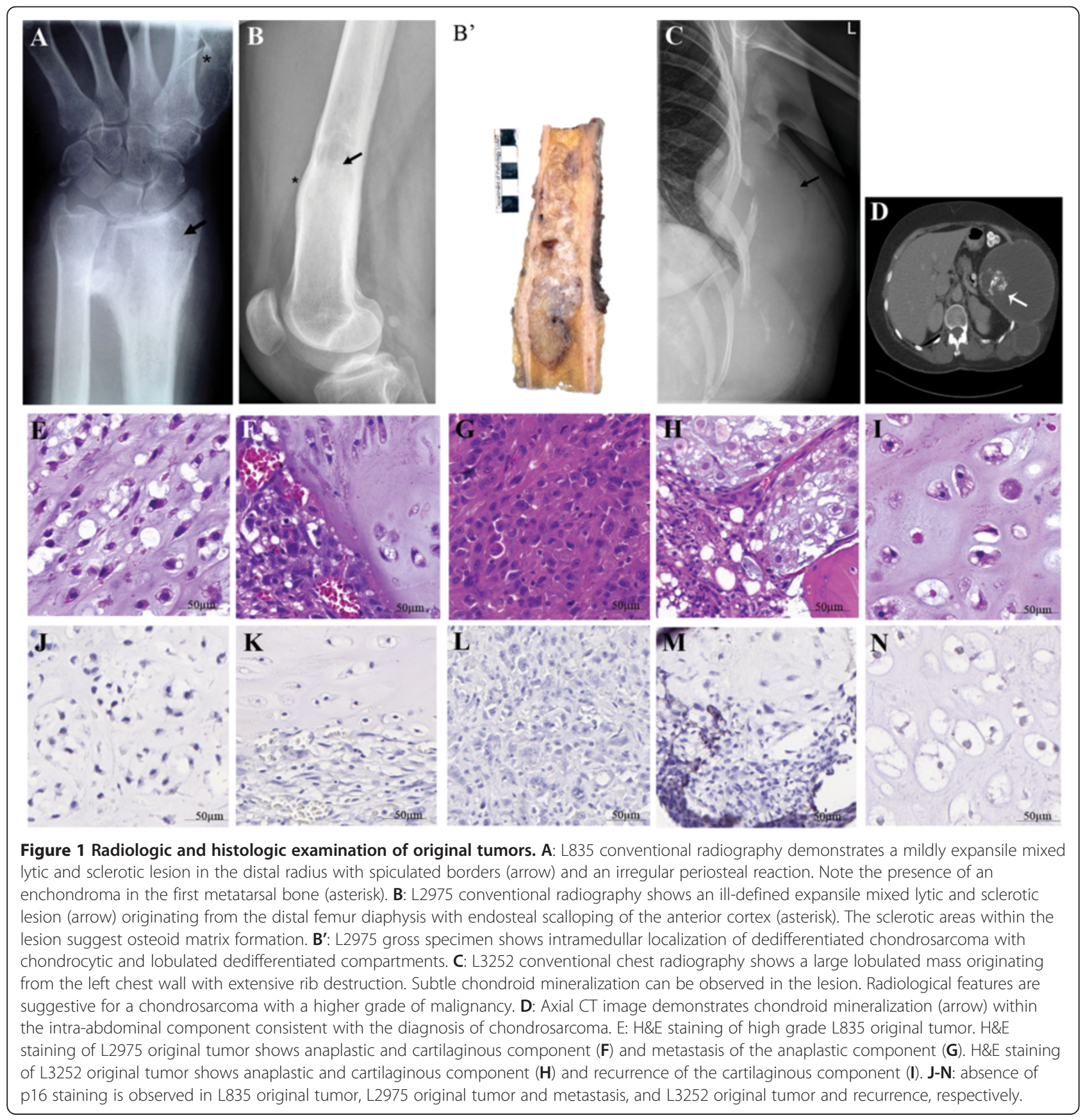


resected eight months earlier (Figure 1B, B'). The primary tumor was $13.6 \mathrm{~cm}$ in size and histological examination revealed two components with a sharp interface indicative of dedifferentiated chondrosarcoma; a grade II chondrosarcoma was juxtaposed to a high grade anaplastic sarcoma (Figure $1 F$ ) with focal deposition of osteoid, indicating differentiation towards osteosarcoma. Histological examination of the spine metastasis revealed exclusively the high-grade anaplastic sarcoma, in which osteoid deposition was absent (Figure 1G).

L3252 is derived from the local recurrence of a chondrosarcoma located at the chest wall (costa) (Figure 1C, D) that had already metastasized to the spine and the lung at the time of first presentation. The primary tumor of this 52 year-old female demonstrated a cellular, partly myxoid and necrotic cartilaginous tumor, with mitoses, indicative of a grade III chondrosarcoma (Figure 1H). However, at local recurrence eight months later, areas of a cartilaginous tumor were intermingled with an anaplastic sarcoma lacking differentiation, indicating dedifferentiated chondrosarcoma. The tissue used for cell culture was derived from an area in which dedifferentiated areas were absent (Figure 1I).

\section{Establishment of cell lines and transmission light microscopy}

L835 was passaged routinely in vitro for 50 generations, L2975 for 60 generations, and L3252 for 30 generations. The cell lines derived from dedifferentiated chondrosarcoma (L2975 and L3252) were noticeably easier to culture than the L 835 cells. This was also reflected by Ki-67 staining on embedded cells, with proliferation rates of $\sim 60 \%$ (L835) versus $\sim 100 \%$ and $\sim 80 \%$ for L2975 and L3252, respectively. The dedifferentiated chondrosarcoma cells were less susceptible to changes in culture conditions reflecting their more aggressive nature. Transmission light microscopy revealed L2975 cells to retain their elongated morphology when in confluence and L3252 cells to detach when reaching confluence (Figure 2A). Identity of cell lines was confirmed using the PowerPlex ${ }^{\circledR} 1.2$ system (Promega Benelux BV, Leiden, The Netherlands). L835 passage 36, L2975 passage 37, and L3252 passage 20 showed identical STR loci when compared to their matching original tumors. Data are available on request. qPCR for expression of cartilage markers revealed expression of ColI, ColIII, aggrecan, and SOX9 in L835 cell line. L2975 cell line expressed ColI, ColIII, ColX, and SOX9. L3252B cell line expressed ColI, ColII, ColIII, ColX, aggrecan, and SOX9.

\section{Migration}

All cell lines were able to migrate. Migration for L835 was at the same rate as cell attachment in the proliferation assay (Figure 2B). For L2975, cell migration occurred much more rapidly than cell attachment (Figure 2C). Moreover, due to high migration efficiency, and the fact that more cells were applied in the migration assay, the cell attachment percentage exceeds that of which is achieved in the proliferation assay. For L3252 cells, migration was observed but only for a small percentage of cells (Figure 2D).

\section{Transplantation into nude mice}

L2975 cells were subcutaneously transplanted into nude mice and a tumor of $4 \mathrm{~mm}$ in diameter was observed in 1 out of 3 mice after 3 months. A fragment of the resulting tumor was subsequently subcutaneously transplanted into 2 nude mice and a tumor of $20 \mathrm{~mm}$ in diameter was observed in 2 out of 2 mice. Morphologically, tumor cells of both the first and second xenograft showed a more epithelioid morphology (Figure 3A, B) while no deposition of cartilaginous matrix was observed at $\mathrm{H} \& \mathrm{E}$ or Toluidine Blue staining (results not shown). Immunohistochemistry showed that $90 \%$ of cells of both xenografts were positive for Ki-67 and were thus actively proliferating (results not shown). Cells obtained from both xenografts were successfully passaged. Xenografting of L835 and L3252 did not result in tumors in 8 months.

\section{COBRA-Fluorescence in-situ hybridization}

The cell line L835 showed a stable karyotype (Figure 4A'). There were many numerical changes with some translocations. The resulting karyotype at passage 35 was: $63-67<3 n>, X Y,-X,+Y,+\operatorname{der}(1 ; 19) t(1 ; 19)$ (p11;p13.3)trp(19)(p13.3p13.2),der(1;19)t $(1 ; 19)(\mathrm{p} 11 ; \mathrm{p} 13.3)$ $\operatorname{trp}(19)(\mathrm{p} 13.3 \mathrm{p} 13.2),-3,-4,+5,-6,+7,-8,-9,-10,-11,+13, \mathrm{t}(14 ; 15)$ (q22;q24),+der(15)t(14;15)(q22;q24)del(15)(q21q24),+16,$17, \mathrm{i}(17)(\mathrm{q} 10),-18,-19,+20,+21,-22$.

L2975 also revealed a stable karyotype at passage 30 with many numerical changes and complex rearrangements (Figure 4B'). The resulting karyotype was: 61$65<3 \mathrm{n}>\operatorname{der}(\mathrm{X} ; 4)(\mathrm{p} 10 ; \mathrm{p} 10), \operatorname{der}(\mathrm{X} ; 8)(\mathrm{q} 10 ; \mathrm{q} 10),-\mathrm{Y},+\operatorname{der}(\mathrm{Y} ; 9)$ (p10;p10)x2,+der(1;15)(q10;q10),der(1;1)(q10;q10)t(1;6) (q21;q24)t(1;8)(q31;p11), der(1;8)(p10;p10), del(2)(q22q32), $-4,-5,+\operatorname{der}(7 ; 15)(\mathrm{q} 10 ; \mathrm{q} 10), \mathrm{t}(9 ; 16)(\mathrm{q} 10 ; \mathrm{q} 10) x 2, \operatorname{der}(10 ; 18)$ (q10;q10),-13, der $(13 ; 13)(\mathrm{q} 10 ; \mathrm{q} 10), \operatorname{der}(14 ; 15)(\mathrm{q} 10 ; \mathrm{q} 10)$ $\mathrm{t}(8 ; 15)(\mathrm{q} 11 ; \mathrm{q} 21),-15,-15,-16,-17, \mathrm{i}(17)(\mathrm{q} 10),-18, \operatorname{der}(18)$ $\mathrm{t}(1 ; 18)(\mathrm{p} 31 ; \mathrm{q} 22), \operatorname{der}(20) \mathrm{t}(\mathrm{X} ; 20)(\mathrm{q} 23, \mathrm{p} 12),-21,+\operatorname{mar} 3 \mathrm{x}$.

L3252 was stable at passage 20 with many numerical changes and complex rearrangements (Figure 4C'): $51<2 \mathrm{n}+>, \mathrm{X},-\mathrm{X},+\operatorname{der}(3 ; 11) \mathrm{t}(3 ; 11)(\mathrm{p} 10 ; \mathrm{q} 10) \mathrm{t}(11 ; 17)(\mathrm{q} 14 ; \mathrm{q} 22)$, $\operatorname{der}(4 ; 8) \mathrm{t}(4 ; 8)(\mathrm{q} 10 ; \mathrm{p} 10), \operatorname{der}(4),+\operatorname{der}(5), \operatorname{der}(6 ; 15) \mathrm{t}(6 ; 15)$ (p10;q10), der(7)t(7;18), der(7), $+\operatorname{der}(8) x 2, \operatorname{der}(8), \operatorname{der}(9)$, der (10),+12, der(13;13)(q10;q10),-13,der(17),i(17)(p10;p10) $\operatorname{der}(18) t(7 ; 18),+\operatorname{der}(20), \operatorname{der}(21),+$ mar. 
A
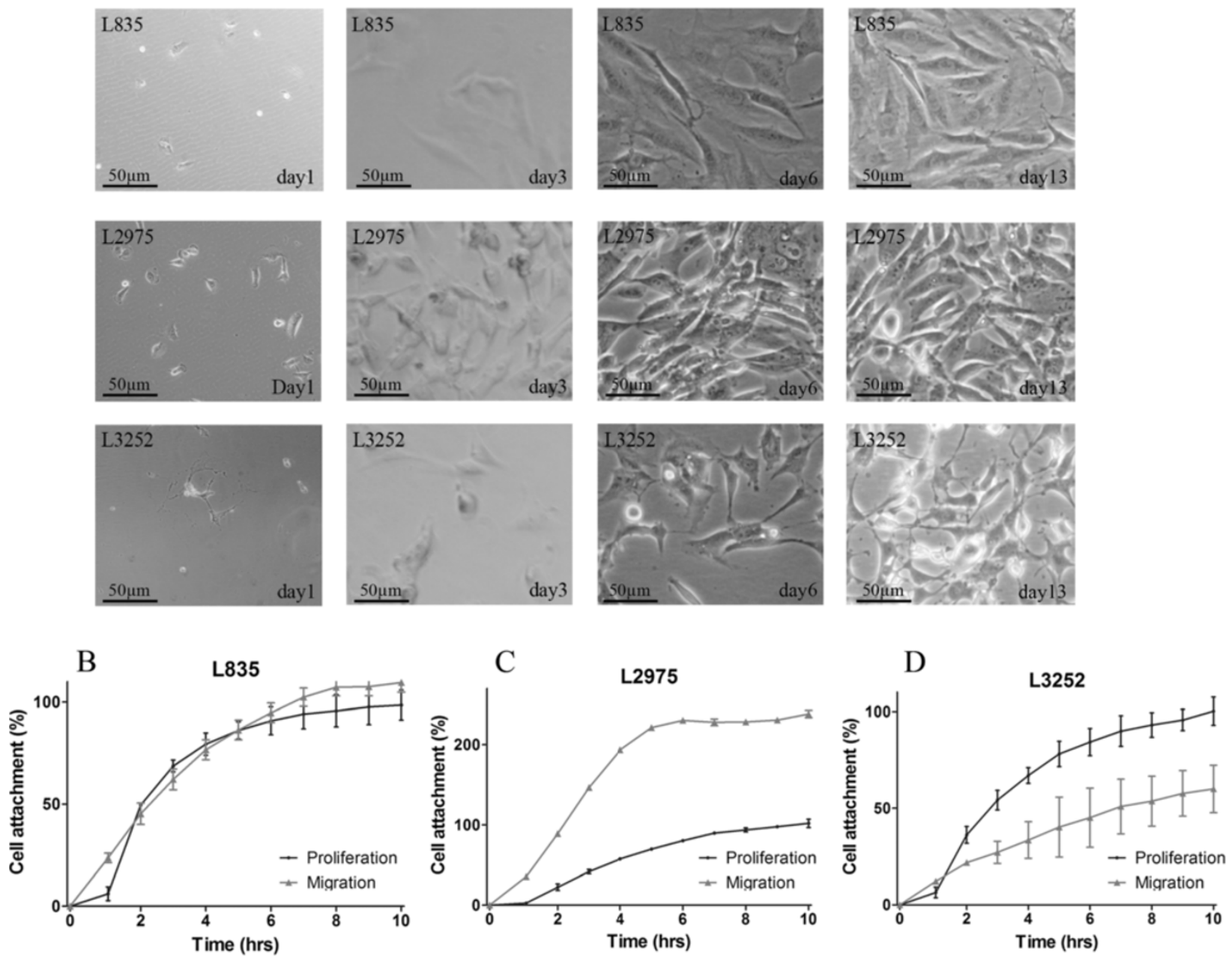

Figure 2 Cell morphology and migration. A: Light microscopy at 40x magnification. Top panel shows L835 cells with round nuclei do not fully populate the flask; day 13 is representative of a full flask for this cell line. Middle panel shows L2975 showing a full flask at day 6 already, multinucleated cells can be observed. Bottom panel shows $L 3252$ still actively dividing, and dividing cells tend to detach and re-attach to the bottom of the flask. B-D Migration plotted against proliferation for the first 10 hours after plating. 1,000 - 10,000 cells were used in the proliferation assay and 100,000 cells in the migration assay. Though all cell lines show migrative capacity, L2975 cells are most successful and have high migrative activity during the first 4 hours after which the slope flattens.

\section{Array-CGH and mutation analyses}

In L835 and L2975, all aberrations present in the tumor were retained in the cell lines. L835 showed a homozygous CDKN2A deletion in both the original tumor and the cell line (Figure 4A"). L2975 and L3252 both showed a homozygous deletion in the cell line (Figure 4B" and $\left.4 C^{\prime \prime}\right)$, the deletion status of the primary tumor was difficult to assess due to low tumor content and consequently resulting suppressed ratio profiles. For both L835 and L2975 clear DNA copy number alterations could be observed in the original tumor samples that were enhanced in the cell lines. For L3252 tumor DNA this was less pronounced. On close examination of the profile, however, one can observe small copy number changes consistent with those observed in the cell line. We previously demonstrated L835 (passage 38) to harbor an IDH1 R132C mutation and L2975 (passage 31) an IDH2 R172W mutation [15]. We here show that L3252 (passage 20) is wild type and that also later passages of L835 (passage 47) and L2975 (passage 46) retain the IDH mutation. Using cDNA we found the mutated IDH alleles to be expressed (results not shown). No hotspot mutations were detected for TP53, PIK3CA, BRAF, KRAS, and EGFR in any of the cell lines.

\section{Immunohistochemical characterization}

Since p16 is frequently silenced in human chondrosarcoma [18] we evaluated p16 in the original tumors, the 


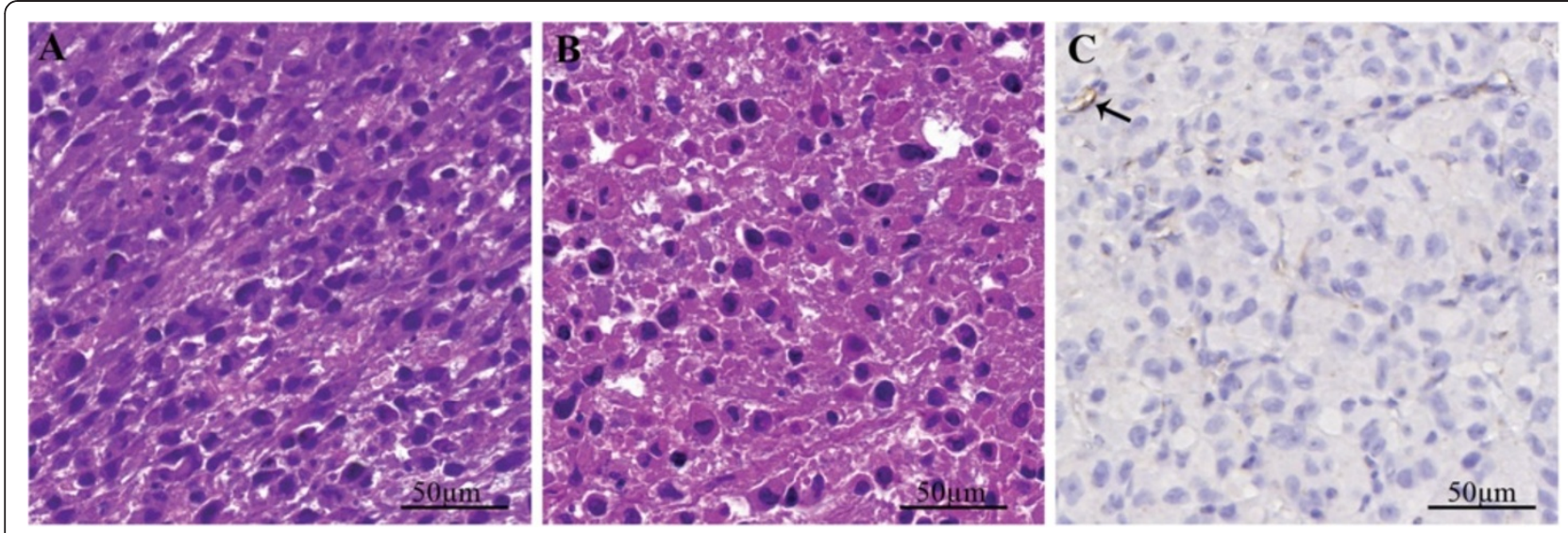

Figure 3 Histologic examination of xenografted L2975. A, B: H\&E stainings of first and second passage of L2975 in nude mice showed L2975 cells had adapted a more rounded morphology. C: p16 staining of first passage confirmed absence of p16 expression; note positive vessel walls (arrow).

cell lines and the L2975 xenografts using immunohistochemistry. All primary tumors (Figure 1J, L, M) and recurrences (Figure 1L, N) were negative for p16. Consistent with the tumor tissue, all derived cell lines lacked p16 protein expression (Table 3), as did xenografts created from L2975 (Figure 3C). We proceeded to test embedded cells from all cell lines shown in Table 3 for p16 expression and found all to be negative. Immunohistochemistry showed nuclear expression of p53 in 10-20\% of the tumor cells in L835 and L3252 primary tumor and cell line, while L2975 tumor, cell line, and xenograft were completely negative (results not shown).

\section{Discussion}

Chondrosarcoma is the second most common primary sarcoma of bone and to date unresectable chondrosarcomas have a poor outcome [3]. Grade III and dedifferentiated chondrosarcomas are extremely aggressive in nature and there is an urgent need for model systems facilitating research in order to develop novel therapeutic strategies. Growing chondrosarcoma cells in culture, however, is a challenge and well growing chondrosarcoma cell lines are sparse. We present here the establishment and characterization of three new chondrosarcoma cell lines originating from grade III and dedifferentiated chondrosarcoma.

Recently chondrosarcoma has been found to harbor IDH1 and IDH2 mutations $(5 ; 15)$ and we published that the mutation is retained in a subset of chondrosarcoma cell lines [15]. In glioma IDH mutations seem to be the earliest event in gliomagenesis even before TP53 mutations occur [20]. In conventional chondrosarcoma we observe a similar phenomenon, where IDH mutations are present already in a high percentage of low-grade tumors and TP53 mutations are observed to increase with grade $(4 ; 5 ; 15)$. Cell lines created from IDH mutant gliomas have been reported to eliminate their IDH mutation under standard culture conditions [7]. Recently, however, a glioma cell line carrying an endogenous IDH1 R132H mutation was published, but this cell line showed a slow growth rate in culture [21]. We here present three chondrosarcoma cell lines, one carrying an IDH1 R132C mutation, one carrying an IDH2 R172W mutation, and one wild type for IDH mutations with stable karyotypes and steady growth patterns. These cell lines show numerical changes and additional mutations. We speculate that in IDH mutant chondrosarcoma the acquisition of additional mutations as we have shown here have facilitated their growth in culture.

The inactivation of tumor suppressor genes is a well-known phenomenon in cancer and p16 mutations have been reported in $20-41 \%$ of human chondrosarcomas [22-25]. Interestingly, all studies observed loss of p16 to be correlated with increasing histological grade in conventional chondrosarcoma. Recently, we showed inactivation of p16 in 30/38 (79\%) dedifferentiated chondrosarcoma cases [26]. We previously published three chondrosarcoma cell lines to be negative for p16 using western blot [18] and upon overexpression of p16 using lentiviral vectors the metabolic activity and cell viability of these cell lines was decreased, indicating loss of p16 to play a role in the proliferative capacity of chondrosarcoma cells. Introduction of p16 in the endogenously TP53 mutant HT-1080 fibrosarcoma cell line, which was recently reported to carry an IDH1 R132C mutation [5], also led to cell cycle arrest and growth inhibition [27-29]. We report here three new chondrosarcoma cell lines lacking p16 expression based on a homozygous deletion of the CDKN2A locus as shown by aCGH analysis, and confirmed loss of p16 expression using immunohistochemistry. Moreover, aCGH analysis showed a copy number loss 


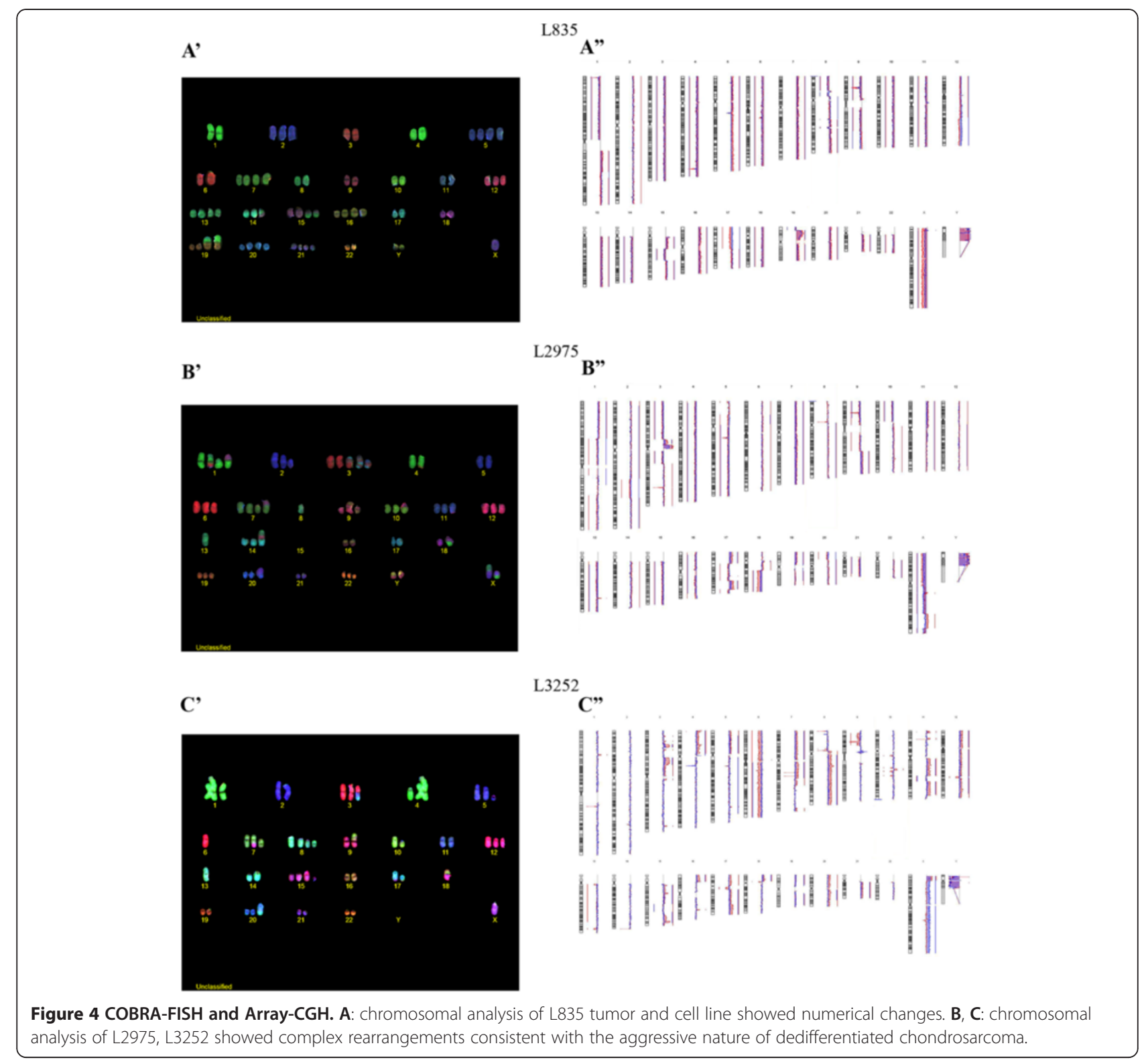

around the 17p13.1 locus in L835, whereas a copy number gain was observed in L2975 and L3252. However, mutation analysis for TP53 showed no activating mutations in exons 5-8, and immunohistochemistry showed no p53 overexpression. Together, our data suggest that while IDH mutations are important as early events in a subset of chondrosarcomas, additional inactivation of p16 may be crucial for acquiring a more aggressive phenotype.

The literature presents us with 5 conventional chondrosarcoma cell lines that have been well characterized using pathological, immunohistochemical, and molecular genetic methods [8,30-32], and we here present L835 as an additional cell line. We previously published L835 to be able to form $3 \mathrm{D}$ pellets [33] and we now show it to be highly stable in culture. L835 cell line showed a slower growth rate compared to the dedifferentiated chondrosarcoma cell lines. In all cases complex genome alterations were observed. Dedifferentiated chondrosarcoma is comprised of two separate components, a high grade anaplastic component and a low to intermediate grade cartilaginous component [2]. The histogenesis has been under debate but evidence points to a single precursor cell with early separation of the two components as a small number of genetic changes is identical in both components, with additional genetic alterations in the anaplastic component [26,34]. Indeed, 3 out of 3 dedifferentiated chondrosarcomas with IDH1 mutations carried the mutation in both components [26]. Moreover, $79 \%$ of the anaplastic and $82 \%$ of the cartilaginous 
Table 3 Overview of chondrosarcoma cell lines and their characteristics

\begin{tabular}{|c|c|c|c|c|c|c|c|c|}
\hline Cell line & Tumor subtype & Histological grade & Passage & $\mathrm{IDH}^{1}$ & $\mathrm{IDH}^{1}$ & $\mathrm{p} 53^{2}$ & $\mathrm{p} 16^{3}$ & Reference \\
\hline \multicolumn{9}{|c|}{ Conventional Chondrosarcoma } \\
\hline SW1353 & Solitary Central & $\|$ & p50 & wt & R172S & V203L & - & ATCC \\
\hline J & Solitary Central & $\|$ & P26 & $\mathrm{R} 132 \mathrm{G}$ & wt & G199V & - & (30) \\
\hline $\mathrm{CH} 3573$ & Solitary Central & $\|$ & P60 & wt & wt & T201- & na & (8) \\
\hline $\mathrm{CH} 2879$ & Solitary Central & III & P31 & G105G & wt & wt & - & (31) \\
\hline OUMS27 & Solitary Central & III & P29 & wt & wt & wt & - & (32) \\
\hline L835 & Solitary Central & III & p51 & $\mathrm{R} 132 \mathrm{C}$ & wt & wt & - & Present Study \\
\hline \multicolumn{9}{|c|}{ Dedifferentiated Chondrosarcoma } \\
\hline L2975 & Dedifferentiated & & p59 & wt & R172W & wt & - & Present Study \\
\hline NDCS1 & Dedifferentiated & & P22 & wt & wt & C242S & - & (9) \\
\hline L3252 & Dedifferentiated & & P26 & wt & wt & wt & - & Present Study \\
\hline
\end{tabular}

${ }^{1} \mathrm{IDH}$ mutations for existing cell lines were described in (15).

${ }^{2}$ p53 mutations for existing cell lines were described in (33).

${ }^{3}$ p16 mutations for existing cell lines were described in (18).

na: not available.

components show loss of p16 expression [26]. L2975 and L3252 were both derived from the recurrence of a dedifferentiated chondrosarcoma; both cell lines exhibited a higher growth rate in vitro, than the L835 cell line, but the cells in culture expressed chondrogenic markers. L2975 proved to be the most aggressive cell line both in culture and in our in vitro migration assay, which may explain why this was the only cell line to be successfully xenografted. We show here the use of L2975 dedifferentiated chondrosarcoma cells with an IDH2 R172W mutation in mouse models, which can be an important asset in the research for new treatment strategies.

\section{Conclusions}

We report the establishment and molecular, genetic and functional characterization of one grade III (L835) and two dedifferentiated chondrosarcoma (L2975 and L3252) cell lines. This represents a substantial addition to the already existing panel of chondrosarcoma cell lines, which together may reflect their heterogeneity. In addition to the existing cell lines these cell lines present the field with an extensive model system as heterogeneous in IDH1 and IDH2 and TP53 mutations as the tumors they are derived from. This panel can be implemented in studies ascertaining human chondrosarcoma tumorigenesis, should provide useful tools in the ongoing search for new targeted therapies, and aid in expanding our knowledge on the role of IDH1 and IDH2 mutations in chondrosarcoma formation.

Competing interests

The authors have no conflict of interest to declare.

\section{Authors' contributions}

$J G V O, J V M G B, K S, P C W H$, and AL-B conceived of the study. JGVO, DdJ,

MAJHVR, IM, and KS performed the experiments. JGVO, JVMG, PDSD, and
CSVR participated in analysis and interpretation of patient data and all authors read and approved the final manuscript.

\section{Financial support}

Netherlands Organization for Scientific Research (917-76-315: J.G.v.O, and J.V M.G.B.), Dutch Cancer Society (UL2010-4873: J.G.V.O. and J.V.M.G.B.). Leiden University Medical Centre and University of Valencia Medical School are partners in the context of EuroBoNet, a European Commission granted Network of Excellence to study the pathology and genetics of bone tumors (018814)

\section{Acknowledgements}

The authors thank Jaap van den Eendenburg, Annemarie Koornneef, Cathelijn Waaijer and Silvia Calabuig Fariñas for expert technical assistance. The authors also thank Anne-Marie Cleton-Jansen for fruitful discussions. The cell lines will be made available upon request for non-commercial use only under the restrictions of an MTA.

\section{Author details}

${ }^{1}$ Department of Pathology, Leiden University Medical Center, Albinusdreef 2 2333 ZA Leiden, The Netherlands. ${ }^{2}$ Department of Medical Cell Biology, Leiden University Medical Center, Albinusdreef 2, 2333 ZA Leiden, The Netherlands. ${ }^{3}$ Department of Orthopedic surgery, Leiden University Medical Center, Albinusdreef 2, 2333 ZA Leiden, The Netherlands. " Department of Radiology, Leiden University Medical Center, Albinusdreef 2, 2333 ZA Leiden, The Netherlands. ${ }^{5}$ Department of Pathology, University of Valencia Medical School, Avda, Blasco Ibañez 17, 46010 Valencia, Spain.

Received: 23 May 2012 Accepted: 20 August 2012

Published: 28 August 2012

\section{References}

1. Bertoni F, Bacchini P, Hogendoorn PCW: Chondrosarcoma. In World Health Organisation classification of tumours. Lyon: IARC Press: Pathology and genetics of tumours of soft tissue and bone. Edited by: Fletcher CDM, Unni KK, Mertens F; 2002:247-251.

2. Milchgrub S, Hogendoorn PCW: Dedifferentiated chondrosarcoma: In World Health Organisation classification of tumours. Lyon: IARC Press: Pathology and genetics of tumours of soft tissue and bone. Edited by: Fletcher CDM, Unni KK, Mertens F; 2002:252-254.

3. Gelderblom H, Hogendoorn PCW, Dijkstra SD, van Rijswijk CS, Krol AD, Taminiau AHM, Bovee JVMG: The clinical approach towards chondrosarcoma. Oncologist 2008, 13(3):320-329.

4. Bovee JVMG, Hogendoorn PCW, Wunder JS, Alman BA: Cartilage tumours and bone development: molecular pathology and possible therapeutic targets. Nat Rev Cancer 2010, 10(7):481-488. 
5. Amary MF, Bacsi K, Maggiani F, Damato S, Halai D, Berisha F, Pollock R, O'Donnell P, Grigoriadis A, Diss T, Eskandarpour M, Presneau N, Hogendoorn PCW, Futreal A, Tirabosco R, Flanagan AM: IDH1 and IDH2 mutations are frequent events in central chondrosarcoma and central and periosteal chondromas but not in other mesenchymal tumours. J Pathol 2011, 224(3):334-343.

6. Yan H, Parsons DW, Jin G, McLendon R, Rasheed BA, Yuan W, Kos I, BatinicHaberle I, Jones S, Riggins GJ, Friedman H, Friedman A, Reardon D, Herndon J, Kinzler KW, Velculescu VE, Vogelstein B, Bigner DD: IDH1 and IDH2 mutations in gliomas. N Engl J Med 2009, 360(8):765-773.

7. Piaskowski S, Bienkowski M, Stoczynska-Fidelus E, Stawski R, Sieruta M, Szybka M, Papierz W, Wolanczyk M, Jaskolski DJ, Liberski PP, Rieske P. Glioma cells showing IDH1 mutation cannot be propagated in standard cell culture conditions. Br J Cancer 2011, 104(6):968-970.

8. Calabuig-Farinas S, Benso RG, Szuhai K, Machado I, Lopez-Guerrero JA, De JD, Peydro A, Miguel TS, Navarro L, Pellin A, Llombart-Bosch A: Characterization of a new human cell line $(\mathrm{CH}-3573)$ derived from a grade II chondrosarcoma with matrix production. Pathol Oncol Res 2012 in press

9. Kudo N, Ogose A, Hotta T, Kawashima H, Gu W, Umezu H, Toyama T, Endo $\mathrm{N}$ : Establishment of novel human dedifferentiated chondrosarcoma cell line with osteoblastic differentiation. Virchows Arch 2007, 451(3):691-699.

10. Yang L, Chen Q, Zhang S, Wang X, Li W, Wen J, Huang X, Zheng J, Huang G, Huang T, Ju G: A novel mutated cell line with characteristics of dedifferentiated chondrosarcoma. Int J Mol Med 2009, 24(4):427-435.

11. Tanke HJ, Wiegant J, Van Gijlswijk RPM, Bezrookove V, Pattenier H, Heetebrij RJ, Talman EG, Raap AK, Vrolijk J: New strategy for multi-colour fluorescence in situ hybrydisation: COBRA: COmbined Binary RAtio labelling. Eur J Hum Genet 1999, 7(1):2-11.

12. Cleton-Jansen AM, van Beerendonk HM, Baelde HJ, Bovée JVMG, Karperien M, Hogendoorn PCW: Estrogen signaling is active in cartilaginous tumors: implications for antiestrogen therapy as treatment option of metastasized or irresectable chondrosarcoma. Clin Cancer Res 2005, 11(22):8028-8035.

13. Atienzar FA, Tilmant $K$, Gerets HH, Toussaint G, Speeckaert S, Hanon E, Depelchin O, Dhalluin S: The Use of Real-Time Cell Analyzer Technology in Drug Discovery: Defining Optimal Cell Culture Conditions and Assay Reproducibility with Different Adherent Cellular Models. J Biomol Screen 2011, 16(6):575-587.

14. Ottaviano L Schaefer KL, Gajewski M, Huckenbeck W, Baldus S, Rogel U, Mackintosh C, de AE, Myklebost O, Kresse SH, Meza-Zepeda LA, Serra M, Cleton-Jansen AM, Hogendoorn PCW, Buerger H, Aigner T, Gabbert HE: Poremba C. Molecular characterization of commonly used cell lines for bone tumor research a trans-European EuroBoNet effort. Genes Chromosomes Cancer 2010, 49(1):40-51.

15. Pansuriya TC, van Eijk R, d'Adamo P, van Ruler MA, Kuijjer ML, Oosting J, Cleton-Jansen AM, van Oosterwijk JG, Verbeke SL, Meijer D, van WT, Nord KH, Sangiorgi L, Toker B, Liegl-Atzwanger B, San-Julian M, Sciot R, Limaye N, Kindblom LG, Daugaard S, Godfraind C, Boon LM, Vikkula M, Kurek KC, Szuhai K, French PJ, Bovée JVMG: Somatic mosaic IDH1 and IDH2 mutations are associated with enchondroma and spindle cell hemangioma in Ollier disease and Maffucci syndrome. Nat Genet 2011, 43(12):1256-1261.

16. van Eijk R, Licht J, Schrumpf M, Talebian YM, Ruano D, Forte Gl, Nederlof PM, Veselic M, Rabe KF, Annema JT, Smit V, Morreau H, van Wezel T, Rapid KRAS: EGFR, BRAF and PIK3CA mutation analysis of fine needle aspirates from non-small-cell lung cancer using allele-specific qPCR. PLOS ONE 2011, 6(3):e17791.

17. De Jong D, Verbeke SL, Meijer D, Hogendoorn PCW, Bovee JVMG, Szuhai K: Opening the archives for state of the art tumour genetic research: sample processing for array-CGH using decalcified, formalin-fixed, paraffin-embedded tissue-derived DNA samples. BMC Res Notes 2011, 4:1.

18. Schrage YM, Lam S, Jochemsen AG, Cleton-Jansen AM, Taminiau AHM, Hogendoorn PCW, Bovee JVMG: Central chondrosarcoma progression is associated with $\mathrm{pRb}$ pathway alterations; CDK4 downregulation and p16 overexpression inhibit cell growth in vitro. J Cell Mol Med 2008, 13(9):2843-2852

19. Evans HL, Ayala AG, Romsdahl MM: Prognostic factors in chondrosarcoma of bone. A clinicopathologic analysis with emphasis on histologic grading. Cancer 1977, 40:818-831.

20. Watanabe T, Nobusawa S, Kleihues $\mathrm{P}$, Ohgaki H: IDH1 mutations are early events in the development of astrocytomas and oligodendrogliomas. Am J Pathol 2009, 174(4):1149-1153.
21. Luchman HA, Stechishin OD, Dang NH, Blough MD, Chesnelong C, Kelly JJ, Nguyen SA, Chan JA, Weljie AM, Cairncross JG, Weiss S: An in vivo patientderived model of endogenous IDH1-mutant glioma. Neuro Oncol 2012, 14(2):184-191

22. Asp J, Sangiorgi L, Inerot SE, Lindahl A, Molendini L, Benassi MS, Picci P: Changes of the p16 gene but not the p53 gene in human chondrosarcoma tissues. Int J Cancer 2000, 85(6):782-786.

23. Asp J, Brantsing C, Lovstedt K, Benassi MS, Inerot S, Gamberi G, Picci P Lindahl A: Evaluation of $\mathrm{p} 16$ and Id 1 status and endogenous reference genes in human chondrosarcoma by real-time PCR. Int J Oncol 2005 27(6):1577-1582

24. Ropke M, Boltze C, Neumann HW, Roessner A, Schneider-Stock R: Genetic and epigenetic alterations in tumor progression in a dedifferentiated chondrosarcoma. Pathol Res Pract 2003, 199(6):437-444.

25. van Beerendonk HM, Rozeman LB, Taminiau AHM, Sciot R, Bovée JVMG, Cleton-Jansen AM, Hogendoorn PCW: Molecular analysis of the INK4A/ INK4A-ARF gene locus in conventional (central) chondrosarcomas and enchondromas: indication of an important gene for tumour progression. J Pathol 2004, 202(3):359-366.

26. Meijer D, de Jong D, Pansuriya TC, van den Akker BE, Picci P, Szuhai K, Bovee JVMG: Genetic characterization of mesenchymal, clear cell, and dedifferentiated chondrosarcoma. Genes Chromosomes Cancer 2012, 51(10):899-909.

27. Fahham N, Sardari S, Ostad SN, Vaziri B, Ghahremani MH: C-terminal domain of p16(INK4a) is adequate in inducing cell cycle arrest, growth inhibition and CDK4/6 interaction similar to the full length protein in HT1080 fibrosarcoma cells. J Cell Biochem 2010, 111(6):1598-1606.

28. Li WW, Takahashi N, Jhanwar S, Cordon-Cardo C, Elisseyeff $Y$, Jimeno J Faircloth G, Bertino JR: Sensitivity of soft tissue sarcoma cell lines to chemotherapeutic agents: identification of ecteinascidin-743 as a potent cytotoxic agent. Clin Cancer Res 2001, 7(9):2908-2911.

29. Rasheed S, Nelson-Rees WA, Toth EM, Arnstein P, Gardner MB: Characterization of a newly derived human sarcoma cell line (HT-1080). Cancer 1974, 33(4):1027-1033.

30. Scully SP, Berend KR, Toth A, Qi WN, Qi Z, Block JA: Marshall Urist Award. Interstitial collagenase gene expression correlates with in vitro invasion in human chondrosarcoma. Clin Orthop Relat Res 2000, 376:291-303.

31. Gil-Benso R, Lopez-Gines C, Lopez-Guerrero JA, Carda C, Callaghan RC, Navarro S, Ferrer J, Pellin A, Llombart-Bosch A: Establishment and characterization of a continuous human chondrosarcoma cell line, ch-2879: comparative histologic and genetic studies with its tumor of origin. Lab Invest 2003, 83(6):877-887.

32. Kunisada T, Miyazaki M, Mihara K, Gao C, Kawai A, Inoue H, Namba M: A new human chondrosarcoma cell line (OUMS-27) that maintains chondrocytic differentiation. Int J Cancer 1998, 77(6):854-859.

33. Van Oosterwijk JG, Herpers B, Meijer D, Briaire-de Bruijn $\mathrm{H}_{\text {, Cleton-Jansen }}$ AM, Gelderblom H, van de Water B, Bovee JVMG: Restoration of chemosensitivity for doxorubicin and cisplatin in chondrosarcoma in vitro: BCL-2 family members cause chemoresistance. Ann Oncol 2012, 23:1617-1626.

34. Bovée JVMG, Cleton-Jansen AM, Rosenberg C, Taminiau AHM, Cornelisse CJ, Hogendoorn PCW: Molecular genetic characterization of both components of a dedifferentiated chondrosarcoma, with implications for its histogenesis. J Pathol 1999, 189:454-462.

doi:10.1186/1471-2407-12-375

Cite this article as: van Oosterwijk et al:: Three new chondrosarcoma cell lines: one grade III conventional central chondrosarcoma and two dedifferentiated chondrosarcomas of bone. BMC Cancer 2012 12:375. 